\title{
Distribution Characteristics and Source of the Heavy Metal in Jianghan Oilfield, China
}

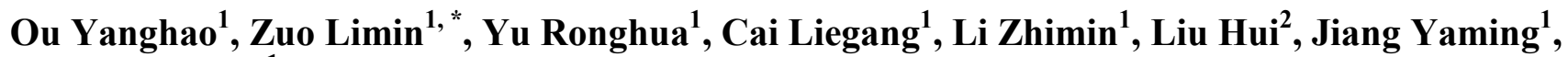 \\ Peng Zhenghua ${ }^{1}$ \\ ${ }^{1}$ Hubei Institute of Hydrogeology and Engineering Geology, Jingzhou, Hu Bei, China \\ ${ }^{2}$ State Key Laboratory of Biogeology and Environmental Geology, China University of Geosciences, Wuhan, Hu Bei, China
}

\section{Email address:}

784903064@qq.com (Ou Yanghao),1606461561@qq.com (Zuo Limin), 3213313854@qq.com (Yu Ronghua)

${ }^{*}$ Corresponding author

\section{To cite this article:}

Ou Yanghao, Zuo Limin, Yu Ronghua, Cai Liegang, Li Zhimin, Liu Hui, Jiang Yaming, Peng Zhenghua. Distribution Characteristics and Source of the Heavy Metal in Jianghan Oilfield, China. Science Discovery. Vol. 4, No. 2, 2016, pp. 65-69.doi: 10.11648/j.sd.20160402.12

Received: March 23, 2016; Accepted: April 11, 2016; Published: May 4, 2016

\begin{abstract}
Selected within Oilfield wells abandoned mine sites, to collect soil samples at different depths to test the heavy metal content, explore the vertical distribution of heavy metal content, combined with the soil texture and the surrounding environment of the samples, the study area to explore sources of heavy metals. Studies have shown that the four heavy metals content are quite different, the lead $(\mathrm{Pb})$ content is inbetween $0.7-33 \mathrm{mg} / \mathrm{kg}$, the nickel $(\mathrm{Ni})$ content is inbetween $13-55 \mathrm{mg} / \mathrm{kg}$, barium $(\mathrm{Ba})$ content is inbetween $110-725 \mathrm{mg} / \mathrm{kg}$, the cobalt $(\mathrm{Co})$ content is $15-60 \mathrm{mg} / \mathrm{kg}$. These four heavy metals are mainly comes from exogenous human activities, including oil exploration, atmospheric deposition, vehicle emissions, manure and fertilizer.
\end{abstract}

Keywords: Jianghan Field, Heavy Metal, Distribution Characteristics, Source Apportionment

\section{中国江汉油田土壤重金属分布特征及来源解析}

欧阳昊 ${ }^{1}$, 左丽敏 ${ }^{*}$, 余荣华 ${ }^{1}$, 蔡烈刚 ${ }^{1}$, 李智民 ${ }^{1}$, 刘慧 ${ }^{2}$, 江亚鸣 ${ }^{1}$, 彭正华 ${ }^{1}$

湖北省地质局水文地质工程地质大队，湖北，荆州，中国

${ }^{2}$ 生物地质与环境地质国家重点实验室与环境学院, 中国地质大学 (武汉), 湖北, 武汉, 中国

\section{邮箱}

784903064@qq. com（欧阳吴），1606461561@qq. com（左丽敏），3213313854@qq. com（余荣华）

中文摘要: 选择江汉油田矿区内废弃油井场地, 在不同深度采样测试重金属含量, 探讨重金属含量的垂向分布特征, 并结合样品的土壤质地及周边环境, 探讨研究区域重金属来源。研究表明, 四种重金属含量差异较大, 铅含量为 $0.7-33$ $\mathrm{mg} / \mathrm{kg}$, 镍含量为 $13-55 \mathrm{mg} / \mathrm{kg}$, 钡含量为 $110-725 \mathrm{mg} / \mathrm{kg}$, 钴含量为 $15-60 \mathrm{mg} / \mathrm{kg}$ 。四种重金属主要来自于外源人类活动, 包括石油开采、大气沉降、汽车尾气排放、畜禽粪便与施肥。

关键词：江汉平原, 重金属, 分布特征, 源解析 


\section{1. 引言}

重金属在土壤中具有稳定性, 隐蔽性, 难以被降解, 近年来, 土壤重金属污染日益严重, 人类生命健康受到严 重威胁, 对重金属污染的研究得到广泛关注 ${ }^{[1-3]}$ 。据调查 可知, 世界每年排放到环境中的重金属, 铜 340 万吨, 采 1.5 万吨, 锰 1500 万吨, 铅 500 万吨, 镍 100 万吨 ${ }^{[4]}$ 。农业 部也报道, 中国重金属污染的耕地面积就达 2000 万公顷, 因此而造成的经济损失达 200 多亿元 ${ }^{[5]}$ 。污染农地中, 有 $80 \%$ 为重金属超标 ${ }^{[6]}$ 。其中, 永、砷、镉、铬、铜、铅、 锌、镍是农业生态环境重点监测的元素 ${ }^{[7]}$ 。重金属污染来 源主要分为自然来源 ${ }^{[8]}$ 与人为来源两种 ${ }^{[9-11]}$, 人为来源一 般有四种: 一是大气沉降, 杨洁等论证中国哈尔滨市城区 大气中Cr、Cu、 $\mathrm{Mn} 、 \mathrm{Ni} 、 \mathrm{~Pb} 、 \mathrm{Zn} 、 \mathrm{Hg} 、 \mathrm{Cd}$ 和As的沉降量较 高 ${ }^{[12]}$, 另有多处报道因燃煤尘与汽车尾气等造成大气中重 金属含量较高, 经沉降进入土壤造成污染 ${ }^{[13-15]}$; 二是矿产 开发 ${ }^{[16]}$, 金属矿山开发残留的废水, 矿渣等未经妥善处置 而造成土壤重金属污染 ${ }^{[17]}$, 也有研究表明, 原油中含有 $\mathrm{Ni}$ 、 $\mathrm{V} 、 \mathrm{Cd}$ 等多种重金属, 会因油田开发进入土壤; 三是污水 灌溉造成土壤重金属污染; 四是固体垃圾 ${ }^{[18]}$ 。

当前, 石油污染土壤存在较为严重的重金属污染, 其 一般主要有三个来源: 一是钻井过程中的添加剂。二是农 药、有机肥、化肥的使用。无机农药如砷酸铅、甲基肿酸 二钠、甲基肿酸钠等是 $\mathrm{As} 、 \mathrm{Zn} 、 \mathrm{~Pb}$ 的重要来源, 磷肥则是 $\mathrm{Zn} 、 \mathrm{Ni} 、 \mathrm{Cu} 、 \mathrm{Co}$ 和 $\mathrm{Cr}$ 的主要来源。三是大气污染物沉降。 大气沉降物中的重金属主要为 $\mathrm{Cu} 、 \mathrm{~Pb} 、 \mathrm{Cd}$ 。有专门的研究
表明中国农业土壤中镍的主要来源依次为: 大气沉降>畜 禽粪便>肥料>污水 $>$ 污泥 $^{[19]}$ 。

本文拟通过研究江汉油田三个废弃油井场地土壤中 重金属的垂向分布规律, 结合其迁移特征, 探讨重金属来 源, 为后期的土壤恢复治理奠定基础。

\section{2. 材料与方法}

\section{1. 研究区域概况}

江汉平原是中国南方重要的油气勘探开发与石油能源 基地, 更是国家商品粮、棉、油基地, 土地主要以农业用 途为主。因石油开采, 造成土壤污染, 农田荒废, 在对其 进行土壤石油污染恢复治理的同时, 检测到重金属含量较 高。本研究选取了中国潜江市境内的三个废弃油井场地, 分别是熊口、后湖、周矶。其中, 后湖井场封闭油井西侧 31 米处为沥青公路, 周矶井场中距封闭油井 $11 \mathrm{~m}$ 处有泥浆池。

\section{2. 土壤样品采集及测试}

在后湖、熊口、周矶三个矿区各自选取封闭油井, 在 井口旁进行浅钻获取岩心, 根据《土壤环境监测技术规范》

$(\mathrm{HJ} / \mathrm{T} 166-2004)$ 的要求, 分别在岩心深度为 $0-0.5 \mathrm{~m}$ 、 $0.5-1 \mathrm{~m} 、 1.5-2 \mathrm{~m} 、 2.5-3 \mathrm{~m} 、 4-4.5 \mathrm{~m} 、 5.5-6 \mathrm{~m}$ 位置采集样品。

将样品带回实验室, 经风干、除杂、磨细, 过篮后, 强酸消化, ICP-AES测定。

表1 采样点分布及样品物理性质。

\begin{tabular}{|c|c|c|c|}
\hline 取样深度 & JH15后湖 & JX08熊口 & JZ09周矶 \\
\hline $0-0.5 \mathrm{~m}$ & 粉土, 松散, 干燥 & 粉土, 松散, 干燥, 含少量植物根系 & $\begin{array}{l}\text { 粘土, 潮湿, 有明显粘滞感, 含大量水草植物 } \\
\text { 根系 }\end{array}$ \\
\hline $0.5^{-1 \mathrm{~m}}$ & 粉土, 稍密, 稍湿, 含少量铁锰质结核 & 粉土, 稍密, 稍湿 & $\begin{array}{l}\text { 粘土, 稍湿, 上部可见少量植物根系, 明显可 } \\
\text { 见石油污染 }\end{array}$ \\
\hline $\begin{array}{l}1.5-2 \mathrm{~m} \\
2.5-3 \mathrm{~m} \\
4-4.5 \mathrm{~m} \\
5.5-6 \mathrm{~m}\end{array}$ & $\begin{array}{l}\text { 粉质粘土, 稍密, 稍湿, 含少量铁锰质结核 } \\
\text { 粉质粘土, 稍密, 稍湿 } \\
\text { 淤泥质粘土, 稍密, 稍湿 } \\
\text { 淤泥质粉质粘土, 稍密, 稍湿 }\end{array}$ & $\begin{array}{l}\text { 粉质粘土, 稍湿, 明显可见石油污染 } \\
\text { 粉土, 稍密, 稍湿 } \\
\text { 粉细砂, 潮湿 } \\
\text { 粉细砂, 潮湿 }\end{array}$ & $\begin{array}{l}\text { 粘土, 稍湿, 含少量铁锰质结核 } \\
\text { 淤泥质粘土, 稍湿, 有粘滞感 } \\
\text { 淤泥质粘土, 潮湿 } \\
\text { 粘土, 稍湿, 含少量铁锰质结核及高岭土 }\end{array}$ \\
\hline
\end{tabular}

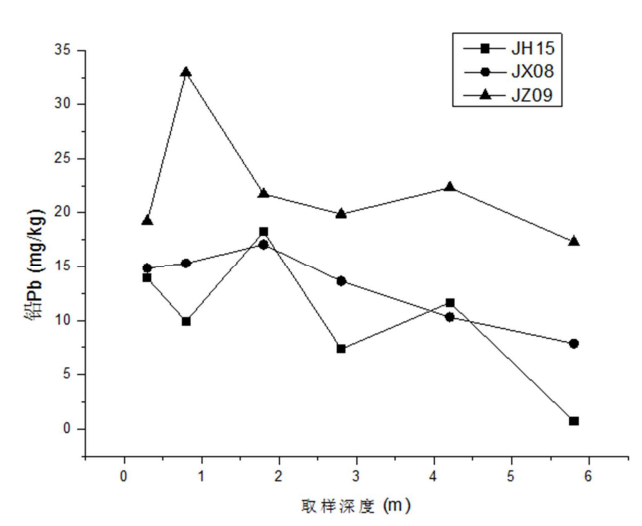

图1 不同深度土壤中铅含量变化曲线图。

\section{3. 结果与讨论}

\section{1. 重金属在土壤中的垂向分布规律}

图1为重金属铅在三个不同区域的土壤中含量随深度 的变化。后湖井场JH15铅含量随着土壤深度的增加, 整体 呈下降趋势, 1.5 到 $2 \mathrm{~m}$ 的深度中铅含量较高, 略有波动。 熊口井场JX08土壤中铅含量随着土壤深度的增加逐渐减 少, 但铅含量在该区域土壤中的下降幅度较小, 仅在 10 到 $15 \mathrm{mg} / \mathrm{kg}$ 的范围内变化。周矶JZ09井场土壤中铅的总含 量较高, 0.5 到 $1 \mathrm{~m}$ 深处的土壤中铅含量最高, 随着土壤深 度的增加, 铅含量明显降低, $3 \mathrm{~m}$ 至 $6 \mathrm{~m}$ 的土壤中铅的含量差 别不大, 分布较均匀。 


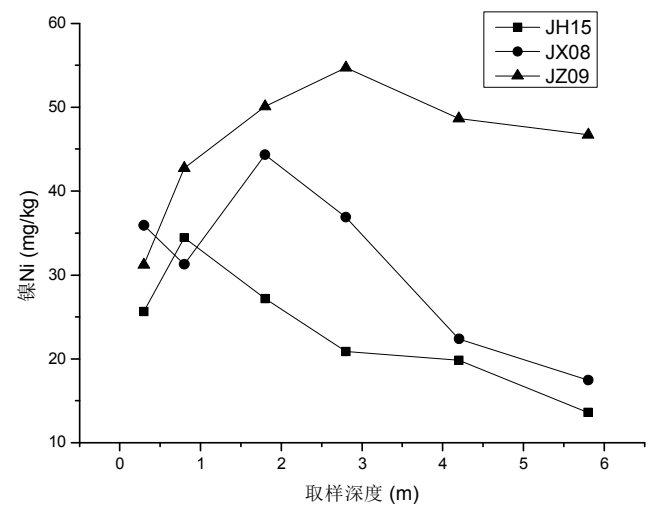

图2 不同深度土壤中镍含量变化曲线图。

如图 2 所示, 后湖及熊口井场的重金属镍在 0 到 $2 \mathrm{~m}$ 深的 土壤中含量较高, 在深层土壤中随着土壤深度的增加, 镍 含量明显降低。周矶井场中镍主要分布在深层土壤中, 2 到 $6 \mathrm{~m}$ 的土壤中镍的含量较高, 达到 $50 \mathrm{mg} / \mathrm{kg}$ 以上。

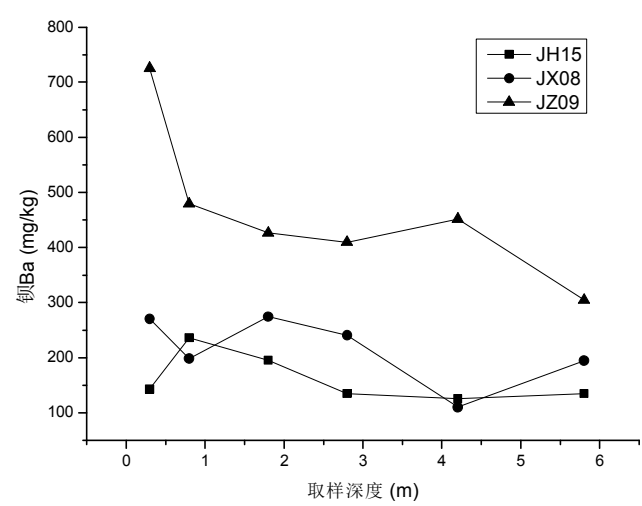

图3 不同深度土壤中钡含量变化曲线图。

如图3所示, 重金属钡在后湖及熊口土壤 0 到 $4 \mathrm{~m}$ 的深度 中, 含量随土壤深度的增加逐渐降低, 之后稍有波动。在 周矶井场土壤中, 其含量随土壤深度的增加, 不断降低, $6 \mathrm{~m}$ 深处与表层土壤中镍含量相差了 $400 \mathrm{mg} / \mathrm{kg}$, 差异较大。

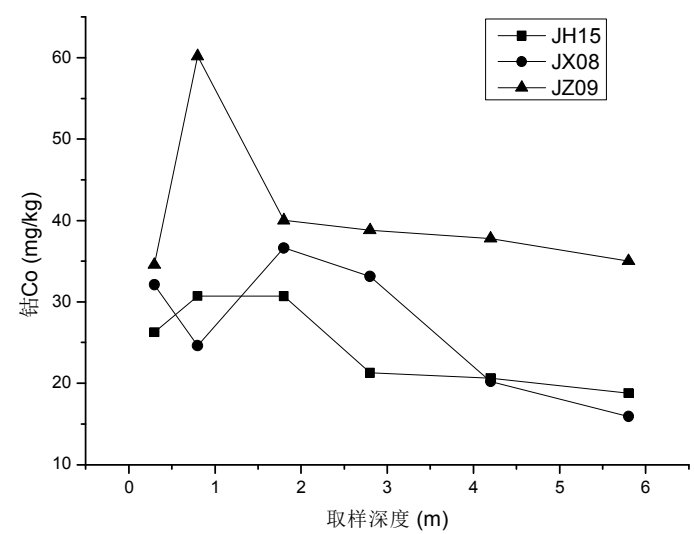

图4 不同深度土壤中钴含量变化曲线图。

图4所示, 重金属钴在三个井场土壤中, 与钡的分布 特征类似。在浅层 0 到 $2 \mathrm{~m}$ 土壤中, 含量上下波动。 $2 \mathrm{~m}$ 以下, 随着土层深度的增加, 钴含量逐渐降低。
综合三个井场的四种重金属的含量, 铅含量为0.7-33 $\mathrm{mg} / \mathrm{kg}$, 镍含量为 $13-55 \mathrm{mg} / \mathrm{kg}$, 钡的含量为 $110-725 \mathrm{mg} / \mathrm{kg}$, 钴含量为 $15-60 \mathrm{mg} / \mathrm{kg}$, 其中钡的含量远高于另外三种重金 属, 镍与钴的含量相近。

\section{2. 土壤中重金属来源解析}

综合图1至图4可知, 不同重金属在近地表土壤中的含 量普遍较高, 除开周矶井场中重金属镍以外, 近地表 $0-2 \mathrm{~m}$ 内土壤中含量均高于深层土壤, 并随着土壤深度的增加含 量逐渐降低。由此说明后湖与熊口井场中的铅、镍、钡、 钴四种重金属以及周矶井场的铅、钡、钴三种重金属主要 来自人类活动 ${ }^{[20]}$ 。三个井场中, JZ09井场土壤中四种重金 属的含量均高于另外两个井场, 根据井场周边环境可知, JZ09井场有泥浆池, JH15与JX08井场没有, 由此说明周矶 井场中重金属主要来源之一为泥浆池。后湖井场的四种重 金属含量与熊口相比较, 普遍偏低, 且熊口井场地表 0-0.5m土壤中重金属含量基本高于深层土壤, 结合两处井 场的周边环境, 熊口井场靠近沥青公路, 车辆偏多, 由此 证明, 熊口井场土壤中重金属主要来源之一为汽车尾气排 放与大气沉降。

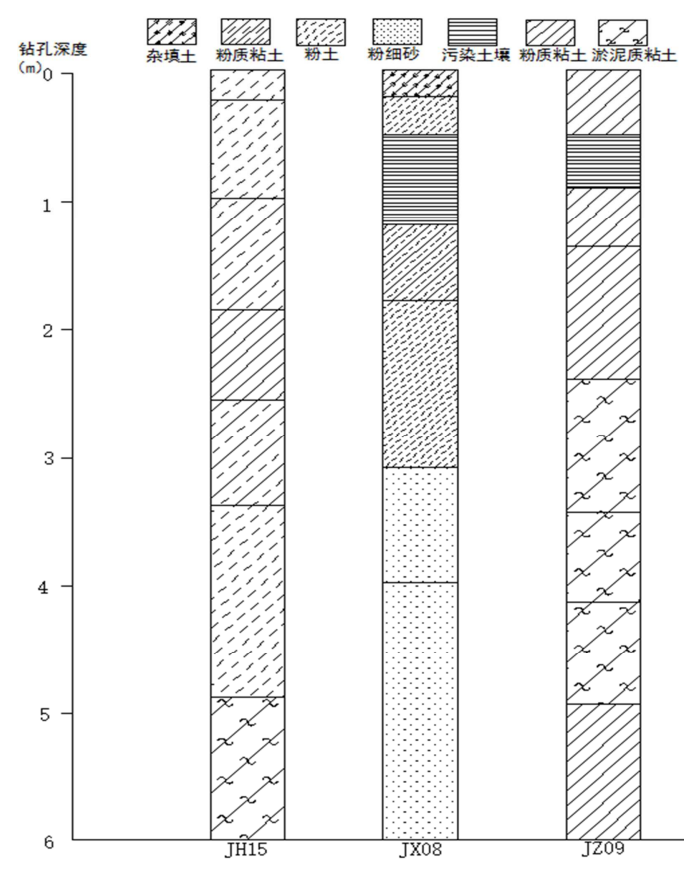

图 5 三个井场钻孔剖面图。

观察三个井场钻孔柱状图（图5）, 熊口井场JX08在 1. 5 到 $2 \mathrm{~m}$ 深的土层可见明显污染土, 对比该区域重金属含 量变化曲线可明显看出, $1.5 \mathrm{~m}$ 到 $2 \mathrm{~m}$ 处土壤中四种重金属含 量明显高于其他深度土壤中重金属含量, 说明该井场重金 属另一主要来源为石油开采。

周矶井场JZ09土壤在0.5到1m深处明显可见污染土， 该深度土壤中重金属钴与铅含量明显高于其他深度土壤 中的含量, 说明钴与铅的主要污染来源之一为石油开采。 钡含量在该土壤中自上而下逐渐降低, 表层含量最高, 表 明钡的主要来源之一为大气沉降 ${ }^{[21]}$ 。周矶井场土壤主要为 
粘土, 比表面积较小, 重金属在该类土壤中的迁移能力降 低, 从铅、钴、钡三种重金属的含量变化曲线也可明显看 出, 曲线在 $2 \mathrm{~m}$ 以下具有明显的转折, 含量下降趋势变缓, 由此推之, 井场中的污染土与泥浆池是铅、钴、钡三种重 金属的另一主要来源。镍含量曲线无规律浮动波动, 表明 该处土壤中重金属的另外一个重要来源为农耕化肥的施 用。镍含量变化不同于其他三种重金属, 其含量随着土壤 深度的增加而增加, 有研究表明, 重金属镍的主要来源依 次为大气沉降 $>$ 畜禽粪便 $>$ 肥料 $>$ 污水 $>$ 污泥, 周矶井场周边 均为农田, 由此说明畜离粪便与肥料是该井场中重金属镍 的主要来源。

后湖井场JH15 土壤中重金属含量整体自上而下呈下 降趋势, 但偶有上下浮动, 结合该井场土壤剖面分析, 土 质为粘土与粉土交替状态, 说明重金属在该区域不同深度 土壤中迁移性不同 ${ }^{[22,23]}$, 因此含量有浮动, 但总体随着深 度增加而降低, 说明其重金属来源主要来自表层, 即大气 沉降。

\section{4. 结论}

（1）三个废弃油井场地的四种重金属中，铅含量为 $0.7-33 \mathrm{mg} / \mathrm{kg}$, 镍含量为 $13-55 \mathrm{mg} / \mathrm{kg}$, 钡的含量为

$110-725 \mathrm{mg} / \mathrm{kg}$, 钴含量为 $15-60 \mathrm{mg} / \mathrm{kg}$ 。

（2）铅、钡、钴、镍四种重金属在近地表 0-2m 内土 壤中含量均高于深层土壤, 并自上而下逐渐减小。除开周 矶井场中重金属镍的含量为表层低于深层土壤。周矶井场 重金属含量远高于后湖及熊口井场。

(3) 周矶井场中重金属主要来源为泥浆池与石油污染 以及畜禽粪便与施肥。熊口井场土壤中重金属主要来源有 石油污染、汽车尾气排放与大气沉降以及农耕化肥的施用。 后湖井场重金属主要来自大气沉降。

\section{致谢}

本文为省科研项目《江汉油田土壤石油污染评价方法 与体系研究》 (No. KJ2015-9) 的阶段性成果之一。

\section{参考文献}

［1］姜芝萍, 杨俊衡. 城市重点污染区土壤重金属污染评价标准 探讨一一以衡阳市某区为例 [J]. 安全与环境工程, 2010, 17 (01) : 57-61。

[2] 廖国礼, 吴超. 矿山环境重金属污染的事故树分析 [J]. 安全 与环境工程, 2006, 13 (03) 29-32。

[3] 倪倩, 蒋敬业, 马振东, 等. 城市工业区湖泊重金属污染状况 - 以武汉墨水湖为例 $[\mathrm{J}]$. 安全与环境工 程, 2005, 12 (01) : 13-16。
[4] 王小庆. 中国农业土壤中铜和镍的生态阈值研究 [D]. 北京: 中国矿业大学 (北京), 2012。

[5] 蒋家焕, 卢礼斌. 重金属污染对水稻生长发育和稻米品质影 响研究现状 [J].福建稻麦科技，2002, 20 (04) : 35-37。

［6］孙波, 周生路, 赵其国. 基于空间变异分析的土壤重金属复 合污染研究 [J]. 农业环境科学学报, 2003, 22 (02) :248-251。

[7] GB 15618-1995土壤环境质量标准 [S]。

[8] 陈怀满. 土壤一植物系统中的重金属污染 [M]. 北京:科学出 版社, 1996。

[9] Mico C, Recatala L, Peris M, et al. Assessing heavy metal sources in agricultural soils of an European Mediterranean area by multivariate analysis[J]. Chemosphere, 2006, 65(5) : 863-872.

[10] Wu S, Zhou S, Li X. Determining the anthropogenic contribution of heavy metal accumulations around a typical industrial town: Xushe, China[J]. Journal of Geochemical Exploration, 2011, 110(2) : 92-97.

[11] Zhao Y, Wang Z, Sun W, et al. Spatial interrelations and multi-scale sources of soil heavy metal variability in a typical urban - rural transition area in Yangtze River Delta region of China[J]. Geoderma, 2010, 156(3-4) : 216-227.

[12] 汤洁, 韩维峥, 李娜, 等. 哈尔滨市城区大气重金属沉降特征 和来源研究 [J]. 光谱学与光谱分析, 2011, 31 (11): 3087-3091。

[13] 陈长林, 李晓所, 张勤, 等. 公路交通对土壤重金属污染的研 究 [J]. 公共卫生与预防医学, 2006, 17 (06) : 19-21。

[14] 张乃明. 大气沉降对土壤重金属累积的影响 $[\mathrm{J}]$. 土壤与环 境, 2001, 10 (02) :91-93。

[15] 高雯媛, 邹霖, 邢宏霖, 等. 邵阳市城区大气降尘中的 $\mathrm{Pb} 、 \mathrm{Cd}$ 的污染及环境风险评价 $[\mathrm{J}]$. 环境污染与防治, 2015, 37 (06) :34-40。

[16] 窦智勇, 程建华, 周平, 等. 基于总量及有效态的铜陵矿区农 田土壤重金属生态风险评价 $[\mathrm{J}]$. 环境污染与防 治, 2015, 37 (11) :6-10。

[17］谭绿贵, 周涛发, 张金金, 等. 矿山金属元素生态环境负效应与 治理对策 $[J]$. 铜陵学院学报, 2005, 02) :54-57.

[18］张永涛, 张增强, 唐次来, 等. 杨凌城市生活垃圾重金属污染 现状评价 $[J]$. 西北农林科技大学学报 (自然科学版), 2007, 35 (01) : 161-165。

[19] Luo L, Ma Y, Zhang S, et al. An inventory of trace element inputs to agricultural soils in China[J]. J Environ Manage, 2009, 90 (8) : 2524-2530.

[20］傅晓文. 盐渍化石油污染土壤中重金属的污染特征、分布和 来源解析 [D]. 山东:山东大学, 2014。 
[21］阮心玲, 张甘霖, 赵玉国, 等. 基于高密度采样的土壤重金属 分布特征及迁移速率 $[\mathrm{J}]$. 环境科学 2006, 27 (05) : 1020-1025。

[22] RUAN XL, Zhang GL, NI LJ, et al. Distribution and Migration of Heavy Metals in UndisturbedForest Soils:A High Resolution Sampling Method[J]. Pedosphere, 2008, 18 (03) : 386-393.
[23] 黄宝荣. 矿山重金属污染土壤化学修复技术研究 [D]. 湖南: 湖南大学, 2004。 